\title{
Ulva rigida (C. Agardh) Makroalginin Fasulye Bitkisinin Üretiminde Organik Madde Kaynağı Olarak Kullanımının Araştırılması
}

\section{Yasemin Özlem ENGİN ${ }^{2} \oplus$ Bülent YAĞMUR ${ }^{1}$ Semra $^{-1}$ CIRIK $^{2} \oplus$ Bülent OKUR ${ }^{1} \oplus$ Dursun EşiYOK Şevket GÖKPINAR ${ }^{2}$}

${ }^{1}$ Ege Üniversitesi Ziraat Fak. Toprak Bilimi ve Bitki Besleme Bölümü, İzmir, Türkiye

${ }^{2}$ Ege Üniversitesi Su Ürünleri Fakültesi Yetiştiricilik Ana Bilim Dalı, İzmir, Türkiye

${ }^{3}$ Ege Üniversitesi Ziraat Fakültesi Bahçe Bitkileri Yetiştirme Bölümü, İzmir, Türkiye

*Sorumlu Yazar: ymnengin@yahoo.com

Geliş 17 Ekim 2018; Kabul 04 Aralık 2018; Basım 01 Haziran 2019.

Alıntılama: Engin' Y. Ö., Yağmur’ B., Cirik, S., Okur’ B., Eşiyok, D., \& Gökpınar, Ş. (2019). Ulva rigida (C. Agardh) makroalginin fasulye bitkisinin üretiminde organik madde kaynağı olarak kullanımının araştırılması. Acta Aquatica Turcica, 15(2), 151-162. https://doi.org/10.22392/actaquatr.577506

Özet

$\mathrm{Bu}$ çalışmada U. rigida (C. Agardh) makroalginin fasulye (Phaseolus vulgaris L. var. nannus cv. Başpınar) yetiştiriciliğinde organik gübre olarak kullanımı araştırılmıştır. Araştırma Ege Üniversitesi Ziraat Fakültesi Bahçe Bitkileri Bölümü uygulama alanında yürütülmüştür. Çalışma saksı denemesi şeklinde planlanmış ve kontrol, ithal deniz yosunu gübresi (Algreen), çiftlik gübresi ve makroalgten (U. rigida) elde edilen kuru biyokütlelerin 5 farklı dozundan oluşan, toplam 8 ayrı uygulama şeklinde yürütülmüştür. Denemelerde Algreen ve çiftlik gübresi tek doz şeklinde uygulanmıştır. Çalışmada en yüksek fasulye verimi $U$. rigida uygulanmış saksılarda elde edilmiş ve $U$. rigida'nın fasulye verimi üzerinde en etkili dozu $150 \mathrm{~g}^{-1}$ saksı olarak tespit edilmiştir. Çalışma sonucunda $U$. rigida alginin fasulye verimi üzerine kontrol ve Algreen uygulamalarından daha etkili $(\mathrm{p}<0.05)$ olduğu saptanmıştır.

Anahtar kelimeler: Makroalg, Ulva rigida, fasulye, organik gübre, verim

The Potential Use of Macroalgae Ulva rigida (C. Agardh) as Organic Matter Source in Common Bean Production

\section{Abstract}

In this study, the use of macro algae U. rigida (C. Agardh) as organic fertilizer in common bean (Phaseolus vulgaris L. var. nannus cv. Başpınar) cultivation was studied. The experiment was conducted in the experimental area of Ege University, Faculty of Agriculture and Department of Horticulture. Bean cultivars were grown in pots. The experiment was consisted of 8 different applications. These were control, imported seaweed based fertilizer (Algreen), farmyard manure and 5 different doses of dried macro algae ( $U$. rigida ). Algreen and farmyard manure were applied as single dose. The highest bean yield was determined in $U$. rigida trials. The most effective dose of $U$. rigida on bean yield was $150 \mathrm{~g} \mathrm{pot}^{-1}$ dose. At the end of the research, it was determined that $U$. rigida was more effective on bean yields compared to Algreen and control group ( $p<$ 0.05) applications.

Keywords: Macroalgae, Ulva rigida, common bean, organic fertilizer, yield

\section{GíRiș}

Makro algler gıda, tarım, tıp, kimya, enerji gibi farklı endüstriyel alanlarda doğrudan ya da hammadde kaynağı olarak kullanılırlar. Dünya genelinde yılda 5-6 milyon ton makro-alg canlı kütle olarak hasat edilmekte, bunun yaklaşık 1milyon tonu toprak zenginleştiriciler ve zirai kimyasalların üretiminde, 1 milyon tonu fikolloid (su yosunlarından elde edilen öz) endüstrisinde ve geri kalan büyük miktar ise gıda olarak değerlendirilmektedir. Dünya genelinde, 43 ülkede toplam 291 makro alg türü kullanılmaktadır. Üretilen 28 milyon ton deniz yosunun 800 bin tonluk kısmı doğadan toplanırken \% 94’ü yetiştiricilik yoluyla elde edilmektedir. Deniz yosunları endüstrisi, dünya ekonomisine yaklaşık 5 milyar USD katkı sağlamaktadır. 
Ülkemizde ise, makro alglerle ilgili olarak akademik düzeyde üretim çalışmaları bulunmasına rağmen ticari üretime bir türlü geçiş yapılamamıştır. Alg üretimine yönelik üniversite - sanayi işbirliği projeleri oluşturularak ülkemizin de bu büyük pazarda bir an önce yer alması sağlanmalıdır. Makro alglerden elde edilen ürünler dünya genelinde 5,5-6 milyar dolar değerinde bir pazar oluşturmaktadır (Ak, 2015).

Deniz alglerinin en eski kullanım alanlarından birisi de gübre olarak değerlendirilmeleridir. Gübre olarak kullanım amacıyla büyük ölçekte makro alg biyokütleleri uzun yıllardan bu yana ticari olarak dünyanın birçok bölgesinde kıyısal alanlardan toplanmaktadır. İngiltere, Norveç, İrlanda, Fransa gibi uzun kıyı şeridine sahip ülkelerde makro alglerin gübre olarak değerlendirilmelerine yönelik bir sanayi gelişmiştir.

Gerek insan sağlığı gerek ekolojik açıdan, katkı maddesi içermeyen ve bazı kimyasal proseslerden geçirilmeyen organik tarım ürünlerine olan talebin artması organik tarımsal girdilerin kullanımını arttırmıştır. Bitkisel ve hayvansal kökenli organik gübrelere ek olarak dünya genelinde ve Türkiye'de deniz yosunu kökenli gübrelerin kullanımının yaygınlaştığı rapor edilmektedir (Eşiyok vd., 2001; Okur vd., 2001).

Ülkemizde sıvı ve katı formda çok sayıda, deniz yosunu gübresi olarak ithal edilen ve farklı ticari isimlerde tescil alarak satışı yapılan ürün bulunmaktadır. Ülkemizde maxicrop ve kelpak gibi ithal deniz yosunu gübrelerinin çeşitli tarımsal ürünlere (üzüm, zeytin, domates, marul vs) olan etkilerinin araştırılmasını konu alan birçok çalışma olduğu bildirilmektedir (Yeşiloğlu ve Tuzcu, 1993; Ay, 1994; Akman, 1995; Özilbey, 1997; Turan ve Köse, 2004).

Türkiye denizlerinde doğal olarak yayılım gösteren bazı deniz yosunlarının organik tarımda kullanılabilirliğine yönelik yapılmış çalışmaların az olduğu rapor edilmektedir (Erdin ve Özsöz, 1983; Cirik vd., 1988; Öztürk, 1994; Çetingül ve Aysel, 1998; Çetingül, 2001;). Genel olarak alglerin metal içeriklerinin belirlenmesini konu alan bu çalışmalar Petalonia, Ulva, Gracilaria, Sargassum, Cystoseria, Enteromorpha ve Dictyopteris cinsi alglerin bazı zirai kimyasallar ve deniz yosunu bazlı gübrelerin üretiminde kullanılabilecek doğal hammadde kaynakları olduğunu desteklemektedir (Erdin ve Özsöz, 1983; Cirik vd., 1988; Çetingül ve Aysel, 1998; Cirik ve Cirik, 1999; Koru ve Cirik, 1999; Çetingül, 2001; Turan, 2007).

Cirik vd. (1988) İzmir Körfezi’nde metallerin deniz vejetasyonu üzerindeki birikimlerini inceleyerek demirin diğer metallere göre daha baskın olduğunu saptamışlardır. Demirkurt vd. (1990), İzmir Körfezinde yaşayan bazı bentik canlılardaki Demir (Fe), Mangan (Mn), Çinko (Zn), Kurşun $(\mathrm{Pb})$, Bakır $(\mathrm{Cu})$, Kadmiyum $(\mathrm{Cd})$ birikim düzeylerinin tespitine yönelik yapmış olduğu çalışmada, $U$. lactuca' da en fazla birikim gösteren metalin Fe olduğunu rapor etmişlerdir.

Çetingül (2001), Petalonia fascia'da miktar olarak en fazla $\mathrm{Fe}$ iz elementinin bulunduğunu, mevsimlere bağlı olmaksızın yüksek miktarda sodyum, potasyum ve azot içerdiğini ve kendi sonuçlarının Vinogradov (1953) ve Murthy ve Radia (1978)'nın yapmış oldukları çalışmalarla paralellik gösterdiğini rapor etmiştir.

Cirik vd. (1988) ile Erdin ve Özsöz (1983) kahverengi alglerle yaptıkları çalışmalarda Mn elementinin Zn'a göre daha yüksek miktarda bulunduğunu saptamışlardır. Aynı istasyondan alınmış bazı kahverengi alglerin çinko içeriği 31,25-360,25 $\mu \mathrm{g} / \mathrm{g}$ (kuru ağırlık) arasında değişim gösterirken, Petalonia fascia' da bu oran 40,02-55,14 mg/kg olarak rapor edilmiştir (Çetingül ve Aysel, 1998; Çetingül, 2001).

Güllüoğlu ve Arığlu (2005), bazı ithal deniz yosunu gübrelerinin (Maxicrop ve Cytozyme) önerilen doz ve zamanlarda soya bitkisine uygulanmasının ekonomik olabileceğini rapor etmişlerdir. Turan ve Köse (2004) yapraktan püskürtme yoluyla verilen sıvı deniz yosunu bazlı bazı ithal gübrelerin, üzümlerde Cu alımını arttırdığını saptamışlardır. Demir vd. (2006) yeşil alglerden Codium tomentosum (Stackhouse), kırmız1 alglerden Gracilaria gracilis (Stackhouse) Steentoft, Irvine et Farnham ve kahverengi alglerden Cystoseira barbata (Stackhouse) C. Agardh'dan elde edilen siviların domates, biber ve patlıcan tohumlarında iki farklı sıcaklıkta çimlenmeye olan etkilerini incelemişler ve kahverengi ve yeşil alg özlerinin biber ve patlıcan tohumlarında her iki sıcaklıkta da çimlenmeyi uyardığını rapor etmişlerdir.

Koç (2013), Giresun ilindeki deniz algleri ve alg ürünlerinin bitki büyümesini stimüle eden çok sayıda bileşikler içerdiklerini ve tarımsal alanda geniş çapta kullanıldığını vurgulamıştır. Araştırıcı çalışmasında gübre ham maddesini oluşturacak algleri (Ulva sp., Corallina sp., Cystoseira sp.) Giresun sahillerinden toplayıp her alg türünden süspanse, sıv1 fermente ve katı formda organik 
gübreler geliştirmiştir. Gübrelerde yapılan analiz sonuçlarına göre her alg türünden elde edilen gübre formlarının organik madde ve bitki besin elementleri yönünden ülkemiz organik gübre standartlarına uygun olduğu araştırıcı tarafından rapor edilmiştir.

Ulva ve Enteromorpha cinsi alglerin iz element kaynakları olarak değerlendirilebileceği birçok araştırmacı tarafından bildirilmektedir (Stenner ve Nickless, 1974; Talbot ve Chegwidden, 1982; Sawidis ve Voulgaropoulos, 1986; Ho, 1990) . Ulva rigida'nın (C. Agardh) Fe elementini Mn, Cu, Zn, ve $\mathrm{Pb}$ gibi diğer iz elementlere oranla daha yüksek miktarda içerdiği bildirilmektedir (Favero vd.,1996).

Deniz marulu olarak da bilinen $U$. rigida Türkiye kıyılarında özellikle sı̆̆ ve kayalık bölgelerde azot ve fosfor gibi besleyici elementlerin bol olduğu kısımlarda doğal olarak yayılım gösteren kozmopolit bir tür olduğu rapor edilmektedir (Cirik ve Cirik, 1999; Cirik, 2001). Stresli koşullara oldukça toleranslıdır. Tuzluluğa dayanıklı bir tür olup, hem tuzlu hem de acı sularda bulunabilmektedir (Şekil 1).

İspanya'nın kuzey batısında patates tarlalarında çalışan araştırıcılar 20, 40 ve $80 \mathrm{t} /$ ha uyguladıkları alg ile klasik gübreleme olan 46,5 t/ha çiftlik gübresi ve 1 t/ha NPK (8:24:16) ile kontrol olarak da gübresiz parseli dikkate almışlardır. Alg gübrelemesi topraklarda asitliği azaltıış, $\mathrm{pH}$ değeri 0,3-0,6 düzeyinde artış göstermiş ve değişebilir kalsiyum miktarı iki katına çıkmıştır. Aynı şekilde $\mathrm{K}$ düzeyinde de belirgin artış rapor edilmiş ve bu artışın tuzlanmaya neden olmadığı belirtilmiştir. $80 \mathrm{t}$ ha-1 alg uygulamasının diğer uygulamalar olan kontrol parseli $(5,5 \mathrm{t} / \mathrm{ha}$ verim) ve klasik gübreleme yapılan parsellere $(8,5 \mathrm{t} / \mathrm{ha}$ verim) göre verim artışında en yüksek değerlere ulaşttğı rapor edilmektedir (Lopez ve Pazos, 1997). Dünya genelinde toplanan tüm yeşil alglerin \% 25'ini Ulva sp türlerinin oluşturduğu bildirilmektedir (Kaykaç vd., 2008). Özellikle B vitamini bakımından çok zengin olup, Japonya başta olmak üzere birçok Uzak doğu ülkesinde denizden toplanmış tallusları tatlı suyla yıkanıp kurutularak veya taze olarak salatalarda ve çorbalarda tüketildiği bildirilmektedir. Ayrıca, gübre olarak tarımda, yem sanayinde, cilt bakım ürünleri olarak kozmetikte ve jel olarak kâğıt yapımında kullanıldığı da rapor edilmektedir (Cirik ve Cirik, 1999; Koru ve Cirik, 1999; Kut vd., 2007; Turan, 2007).

Özdemir vd. (2016) Chlorella vulgaris mikro alginin üretilmesi ve biyogübre olarak kullanımının domates bitkisi üzerinde bitki gelişimi, verim ve meyve kalitesine etkilerini araştırmışlar ve serada organik domates yetiştiriciliğinde 3 farklı formda [toprağa toz alg uygulaması (2,5 g/fide), toprağa sıvı alg uygulaması (250 mL fide-1) ve yaprağa sıvı alg spreylenmesi] alg uygulaması yapmışlardır. Elde edilen sonuçlar $C$. vulgaris'in bitki gelişimi, verim ve bazı meyve kalite parametrelerini (kuru ağırlık, toplam suda çözünür kuru madde, titre edilebilir asit ve vitamin C) artırdığını, kullanılan uygulamalar içerisinde özellikle toprağa kuru alg uygulamasının daha iyi sonuçlar verdiğini ve doğa dostu bir gübre olarak C. Vulgaris'in organik tarımda kullanılabileceğini göstermiştir

Makro algler İzmir Körfezi'nde yoğun biyokütleler oluşturmaktadır. Kıyısal alanlarda yığınlar oluşturan makro algler kirlilik yaratmaktadır. U. rigida, İzmir Körfezi’nde diğer alg türlerine göre daha yüksek biyokütleler oluşturmaktadır. Bu çalışmada; ülkemiz kıyılarında doğal olarak dağılım gösteren deniz makro alglerinden $U$. rigida'nın fasulye (Phaselous vulgaris L.) bitkisi yetiştiriciliğinde alternatif organik gübre kaynağı olarak kullanılabilirliği araştırılmıştır. Algler mineral içerikleri bakımından bitki besin maddelerinin büyük bir kısmını içermekte ve bu nedenle de tarımsal üretimde gübrelere alternatif olarak değerlendirilmektedir. Bu çalışma kapsamında da $U$. rigida makro alginin fasulye bitkisinin verimine olan etkileri saksı denemeleri yapılarak incelenmiştir.

\section{MATERYAL ve YÖNTEM}

\section{Materyal}

Araştırma Ege Üniversitesi Ziraat Fakültesi Bahçe Bitkileri Bölümü Uygulama alanında saks1 denemeleri şeklinde yürütülmüss, denemelerde saksı toprağı olarak organik üretim yapılan alanlardan alınan toprak kullanılmıştır. 


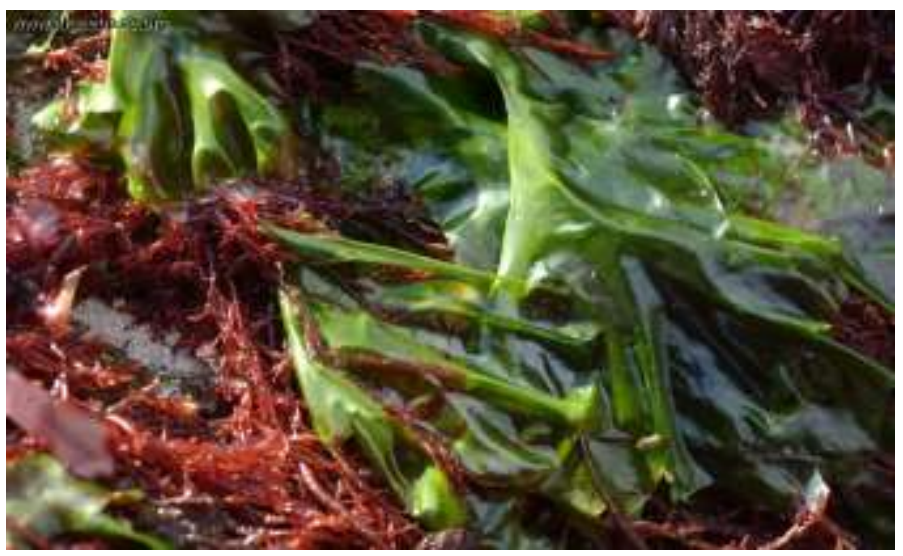

Şekil 1. $U$. rigida'nın görünümü

İzmir Körfezi Bostanlı kıyılarında özellikle ilkbahar döneminde yüksek biyokütleler oluşturarak kıyısal alanlarda birikerek kirliliğge neden olan ve bu nedenle İzmir Büyükşehir Belediyesi tarafından toplatılıp atılan yeşil alglerden [(Chlorophyta) Ulva rigida Ag.)] elde edilen biyokütleler (Şekil 1), bu çalışmada organik gübre materyali olarak kullanılmıştır. Alg biyokütleleri İzmir Büyükşehir Belediyesi ile oluşturulan protokol kapsamında İzmir Körfezi Bostanlı kıyılarından Mayıs ve Haziran aylarında toplanmıştır (Şekil 2).

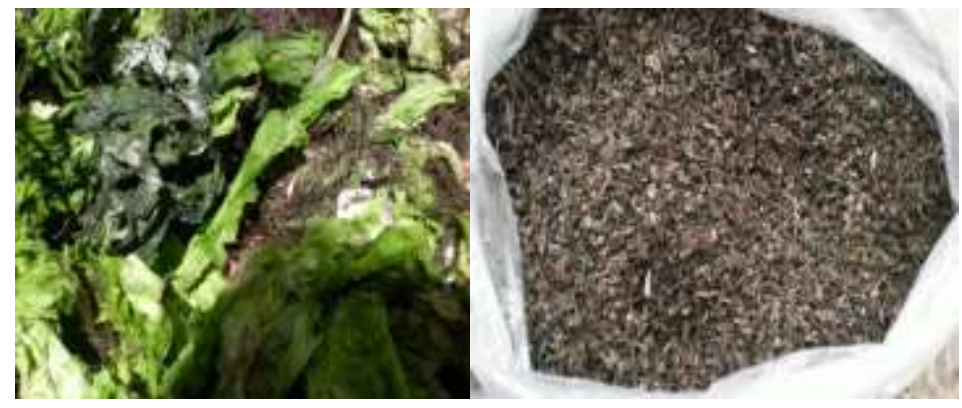

Şekil 2. Denemede kullanılan makro alg biyokütleleri

Gübre olarak kullanıma yönelik gerekli bazı analizlerin yapılabilmesi için toplanan makro alg Ege Üniversitesi Su Ürünleri Fakültesi Urla yerleşkesinde ön işlemlere tabii tutulmuştur. Makro alg biyokütleleri, su dolu tanklarda 1 gün süreyle bekletildikten sonra çeşme suyu ile yıkanarak, serada 5 gün boyunca kurumaya bırakılmıştır (Şekil 3). Kurutma işlemi tamamlandıktan sonra makro alg biokütleleri Ege Üniversitesi Ziraat Fakültesi Toprak Bilimi ve Bitki Besleme Bölümü laboratuvarında ögütülerek toz haline getirilmiştir (Şekil 4) .

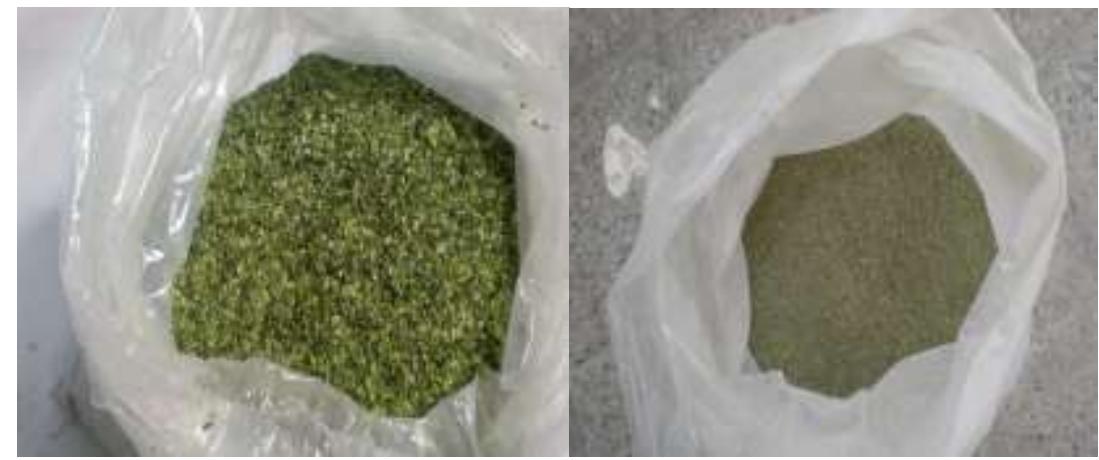

Şekil 3-4. Kurutulmuş $U$. rigida biyokütleleri - öğütülmüş $U$. rigida materyali

Denemede kullanılan organik gübrelere ( $U$. rigida, çiftlik gübresi ve ithal deniz yosunu gübresi) ait bazı kimyasal analiz sonuçları Tablo 1'de verilmiştir. Hafif asit reaksiyon gösteren alg örneğinde, 
organik madde ve toplam azot içeriği yüksek düzeyde bulunmaktadır. Toplam P içeriği düşük olan örnekte, toplam $\mathrm{K}, \mathrm{Ca}, \mathrm{Mg}, \mathrm{Na}$ içeriği yüksek; toplam $\mathrm{Fe}, \mathrm{Cu}, \mathrm{Zn}, \mathrm{Mn}$ içeriği ise yeterli düzeydedir. Hafif alkali reaksiyon özelliği gösteren çiftlik gübresi örneğinde organik madde içeriği yüksek, toplam azot ve $\mathrm{P}$ içeriği orta düzeydedir. Toplam $\mathrm{K}, \mathrm{Ca}, \mathrm{Mg}, \mathrm{Fe}, \mathrm{Cu}, \mathrm{Zn}$ ve $\mathrm{Mn}$ içeriği ise yüksek düzeydedir. Çok kuvvetli alkali reaksiyon gösteren Algreen'in toplam organik madde, $\mathrm{N}, \mathrm{P}, \mathrm{K}, \mathrm{Ca}, \mathrm{Mg}$ ve $\mathrm{Fe}$ içeriği yüksek düzeyde saptanmıştır.

Yemeklik baklagillerden olan fasulye (Phaseolus vulgaris L. var. nannus cv. Başpınar) kuru ve taze olarak tüketilen, yüksek protein içeriğiyle insan beslenmesinde ve bitki artıklarıyla da yem sanayinde kullanılan önemli bir kültür bitkisidir. Meyve gelişmesi için en uygun sıcaklığın $15-20{ }^{\circ} \mathrm{C}$ olması gerekir ve düşük toprak sıcaklıkları çimlenmeyi olumsuz etkiler. Çiçeklenme ve meyve bağlama dönemindeki yüksek sıcaklıklar verim ve kalite kayıplarına yol açar (Eşiyok ve Bozokalfa, 2007).

Tablo 1. U. rigida, çiftlik gübresi ve ithal deniz yosunu (Algreen) gübresinin kimyasal özellikleri

\begin{tabular}{llll}
\hline \hline Parametreler & U. rigida & $\begin{array}{l}\text { Çiftlik } \\
\text { gübresi }\end{array}$ & Algreen \\
\hline pH & 6,35 & 7,72 & $9-11$ \\
Organik madde1 & 40,08 & 68,50 & 55,00 \\
Toplam Azot 1 & 2,576 & 1,42 & 1,00 \\
Toplam Fosfor 1 & 0,17 & 0,85 & 2,61 \\
Toplam Potasyum 1 & 2,73 & 2,24 & 15,00 \\
Toplam Kalsiyum1 & 1,32 & 1,32 & 1,17 \\
Toplam Magnezyum1 & 2,98 & 0,42 & 1,42 \\
Toplam Demir1 & 0,016 & 0,08 & 1,06 \\
Toplam Bakır2 & 10,05 & 41,00 & -- \\
Toplam Çinko2 & 29,59 & 206,00 & -- \\
Toplam Mangan2 & 95,25 & 224,00 & -- \\
Aljinik Asit1 & -- & -- & 20,00 \\
Mannitol1 & -- & - & 0,70 \\
Sitokinin. IAA. ABA. Betainler ve Amino Asit & - & - & 0,25 \\
Toplam11 & - & &
\end{tabular}

\section{Yöntem}

Çalışma; kontrol, ithal deniz yosunu gübresi (Algreen $\left.{ }^{\circledR}\right)$, çiftlik gübresi ve makro alg ( $U$. rigida)'in 5 farklı dozundan oluşan 8 ayrı uygulama şeklinde, tesadüf parselleri deneme desenine göre 3 tekerrürlü olarak yürütülmüştür (Tablo 2). Denemede fasulye tohumları organik bahçe toprağı ile doldurulmuş ve 24 adet saksıya $(75 \times 26 x 21 \mathrm{~cm})$ her saksıda 10'ar adet bitki olacak şekilde 12 Eylül 2015 yılında ekilmiş, 2 ay sonra deneme sonlandırılmıştır.

Tablo 2. Saksı deneme deseni

\begin{tabular}{lll}
\hline \hline I.Tek. & II. Tek. & III. Tek. \\
\hline Kontrol & Çiftlik & Algreen \\
Çiftlik & Algreen & U. rigida 1 \\
Algreen & U. rigida 4 & U. rigida 3 \\
U. rigida 1 & U. rigida 2 & U. rigida 2 \\
U. rigida 5 & U. rigida 1 & U. rigida 4 \\
U. rigida 3 & U. rigida 5 & $U$. rigida 5 \\
$U$. rigida 4 & U. rigida 3 & Kontrol \\
$U$. rigida 2 & Kontrol & Çiftlik \\
\hline \hline
\end{tabular}

Fasulye denemesine ait bir görüntü ile deneme konularından elde edilen fasulye bitkilerine ait bir diğer görüntü Şekil 5 ve 6'da, denemenin kurulduğu İzmir ili Bornova İlçesi iklim verileri ise Tablo 3'te verilmiştir. 


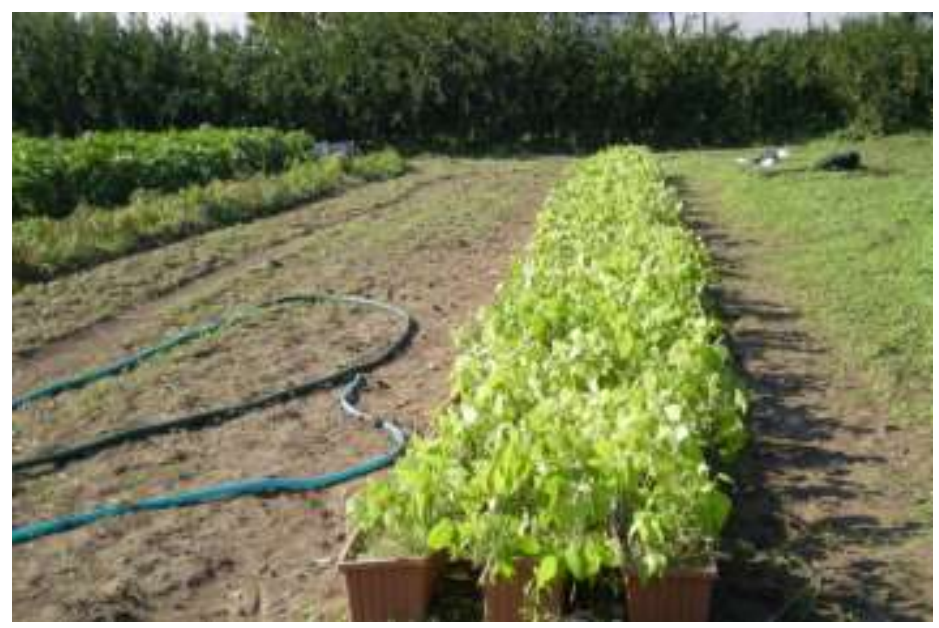

Şekil 5. Fasulye denemesinden bir görünüm

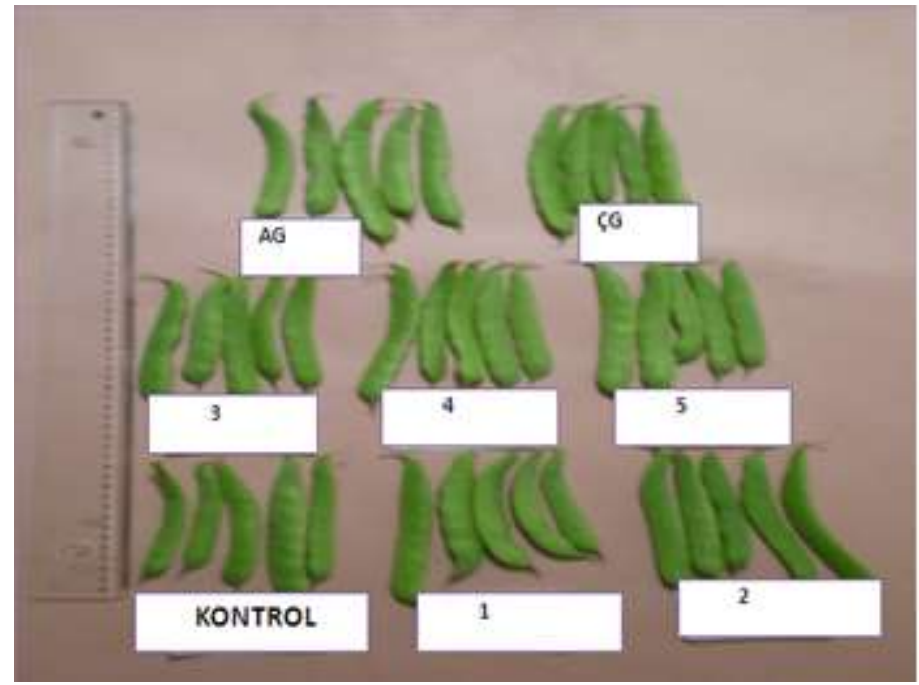

Şekil 6. Uygulamalardan hasat sırasında alınan fasulye bitkileri (AG:Algreen, ÇG:Çiftlik Gübresi, 1:U. rigida 1; 2:U. rigida 2 3:U. rigida 3; 4: $U$. rigida 4; 5: U. rigida 5)

Tablo 3. Denemelerin yapıldığı döneme ait ortalama, maksimum ve minimum sıcaklık ile nispi nem değerleri (MGM, 2015)

\begin{tabular}{lcccccccccccc}
\hline \hline \multirow{2}{*}{ İklimsel değerler } & \multicolumn{10}{c}{ Aylar } \\
\cline { 2 - 11 } & $\mathbf{9}$ & $\mathbf{1 0}$ & $\mathbf{1 1}$ & $\mathbf{1 2}$ & $\mathbf{1}$ & $\mathbf{2}$ & $\mathbf{3}$ & $\mathbf{4}$ & $\mathbf{5}$ & $\mathbf{6}$ & $\mathbf{7}$ & $\mathbf{8}$ \\
\hline Ort. Sicaklık $\left({ }^{\circ} \mathrm{C}\right)$ & 24,4 & 19,6 & 13,9 & 9,0 & 7,5 & 9,3 & 15,2 & 18,0 & 21,0 & 26,9 & 28,5 & 29,2 \\
Maks. Sicaklık $\left({ }^{\circ} \mathrm{C}\right)$ & 30,0 & 24,5 & 18,3 & 12,8 & 11,9 & 13,9 & 19,6 & 22,6 & 26,5 & 32,2 & 33,6 & 34,0 \\
Min. Sicakl1k $\left({ }^{\circ} \mathrm{C}\right)$ & 19,5 & 16,0 & 11,2 & 6,3 & 4,4 & 5,7 & 11,8 & 14,3 & 15,2 & 21,5 & 23,8 & 24,5 \\
Nisbi Nem $(\%)$ & 48,5 & 64,6 & 69,4 & 69,9 & 61,6 & 59,9 & 61,0 & 55,7 & 49,9 & 44,1 & 40,3 & 45,2 \\
\hline \hline
\end{tabular}

Denemede kurutulmuş ve öğütülmüş makro-alg biyokütleleri 5 farklı doz (U. rigida 1: $150 \mathrm{~kg} / \mathrm{da}$; U. rigida 2: $300 \mathrm{~kg} / \mathrm{da}$; U. rigida $3: 450 \mathrm{~kg} / \mathrm{da}$; U. rigida $4: 600 \mathrm{~kg} / \mathrm{da}$ ve $U$. rigida $5: 750 \mathrm{~kg} / \mathrm{da}$, çiftlik gübresi tek doz (5 ton/da) ve ithal deniz yosunu gübresi (Algreen WSG - 600) ise firmanın önerdiği miktar dikkate alınarak tek doz şeklinde (60 g/da) saksılara uygulanmıştır (Tablo 4). Denemeye ait toprak örneklerinde $\mathrm{pH}$, toprak macununda $\mathrm{pH}$ metre ile (Black, 1965), eriyebilir toplam tuz ise elektrik direnç aleti ile ölçülmüştür (U.S. Soil Survey Staff, 1993). Kireç Scheibler kalsimetresi ile (Schlichting ve Blume, 1966), bünye hidrometre yöntemi ile (Bouyoucos, 1962), organik madde Reuterberg ve Kremkus yöntemine göre (Black,1965), toplam azot (Bremner, 1965), alınabilir fosfor Bingham (1949), değişebilir katyonlar olan $\mathrm{Na}, \mathrm{K}, \mathrm{Ca}, \mathrm{Mg}$ elementleri $1 \mathrm{~N}$ Amonyum asetat yöntemine göre belirlenmiştir (Pratt, 1965). Topraktaki mikro elementler olan $\mathrm{Fe}, \mathrm{Cu}, \mathrm{Zn}, \mathrm{Mn}$ (Linsday ve Norvell, 1978)'e göre yapılmıştır. Alg örneklerinde ve ahır gübresinde; $\mathrm{pH}$, yine sature 
edilen ekstrakta $\mathrm{pH}$ metre ile organik madde Reuterberg ve Kremkus yöntemine göre (Black, 1965), toplam azot (Kacar, 1984), alınabilir fosfor (Loot ve ark. 1956), makro ve mikro elementler ile değişebilir katyonlardan $\mathrm{Na}, \mathrm{Ca}, \mathrm{Mg}, \mathrm{K}$ elementleri Kacar (1972) ve Kacar (1984)'a göre analiz edilmiştir.

Tablo 4. Denemede kullanılan farklı gübre materyalleri ve uygulanan doz miktarları

\begin{tabular}{lcc}
\hline \hline Gübreler & $\begin{array}{l}\text { Uygulama miktarı } \\
\text { (gr/saksı) }\end{array}$ & $\begin{array}{l}\text { Uygulama miktarı } \\
\text { (kg/da) }\end{array}$ \\
\hline Kontrol & 0 & 0 \\
$U$. rigida 1 & 30 & 150 \\
U. rigida 2 & 60 & 300 \\
$U$. rigida 3 & 90 & 450 \\
$U$. rigida 4 & 120 & 600 \\
$U$. rigida 5 & 150 & 750 \\
Çiftlik Gübresi & 500 & 5 ton da-1 \\
Algreen & 0.012 & 60 gr da-1 \\
\hline \hline
\end{tabular}

Toplam 24 adet saksıdan hasat edilen fasulyelerin saksı verimlerini belirlemek amaciyla çalışma sonunda elde edilen verilere, bilgisayarda Tarist istatistiksel analiz paket programı kullanılarak varyans analizi uygulanmış ve ortalamalar arasındaki farklılıkları belirlemek için LSD (En Küçük Anlamlı Fark Testi, Least Significant Difference Test) testi yapılmıştır (Açıkgöz,1994).

\section{TARTIŞMA ve SONUÇ}

Denemelerde kullanılan toprak örneğinin fiziksel ve kimyasal özellikleri Tablo 5'te verilmiștir. Hafif alkali reaksiyona sahip toprak örneğinde tuzluluk yönünden herhangi problem bulunmamaktadır. Kireçli olan toprak örneği kumlu killi tın bünye özelliği göstermektedir. Organik maddece fakir, toplam azotça orta düzeyde olan toprak örneğinde alınabilir makro ve mikro besin elementleri yeterli (alınabilir Fe orta ) düzeyde bulunmaktadır.

Tablo 5. Denemede kullanılan toprak örneğinin bazı fiziksel ve kimyasal özellikleri

\begin{tabular}{ll}
\hline \hline Parametre & Değer \\
\hline pH & 7,56 \\
Toplam Tuz1 & 0,100 \\
Kireç1 & 4,22 \\
Kum1 & 54,56 \\
Mil1 & 20,00 \\
Kil & 25,44 \\
Bünye & Kumlu Killi Tın \\
Organik Madde1 & 1,67 \\
Toplam Azot1 & 0,100 \\
Alınabilir Fosfor2 & 3,37 \\
Alınabilir Potasyum2 & 224 \\
Alınabilir Kalsiyum2 & 3600 \\
Alınabilir Magnezyum2 & 185 \\
Alınabilir Sodyum2 & 37 \\
Alınabilir Demir2 & 2,89 \\
Alınabilir Bakır2 & 0,98 \\
Alınabilir Çinko2 & 1,01 \\
Alınabilir Mangan2 & 12,10 \\
\hline \hline 1: \%;2: mg/kg
\end{tabular}


Çiftlik gübresi, ithal deniz yosunu gübresi ve $U$. rigida alginden elde dilen materyalin fasulye saks1 verimi üzerine olan etkilerini belirlemek amacıyla yapılan çalışmadan elde edilen bulgular sırasıyla Tablo 6 ve Tablo 7'de verilmiştir.

Tablo 6 ve 7 incelendiğinde uygulamaların verim üzerine etkisi istatistiki açıdan önemli $\% 5$ ve \%1 seviyesinde önemli bulunmuştur. Tüm uygulamalar arasında en yüksek fasulye saksı verimi (150 $\mathrm{g} / \mathrm{saks1})$ U. rigida alginin 5. doz uygulamasında elde edilmiştir. Bunu sırasıyla $U$. rigida 4.doz (141g/saksı), Çiftlik gübresi (128 g/saksı), U. rigida 3. doz (126 g/saks1), Algreen (122 g/saks1), $U$. rigida 2. doz (116 g/saks1), U. rigida $1 . d o z$ (115 g/saks1) ve son olarak kontrol grubu (114 g/ saks1) uygulamaları izlemiştir. Çalışmada $U$. rigida'nın 4. doz ve 5. dozlarının çiftlik gübresi ve ithal deniz yosunu gübresi (Algreen) uygulamalarından daha etkili olduğu saptanmıştır. Bununla birlikte makroalgten elde edilen materyalin düşük dozlarda (30-60 gr/saksı) uygulamasının fasulye saks1 verimi üzerine önemli bir etkisinin olmadığı ancak kontrole göre bir miktar verim artışı( \%1-2) sağladığı; asıl önemli etkinin doz artışına bağlı olarak geliştiği saptanmıştır.

Tablo 6. Denemeden elde edilen fasulye verim değerleri (g saks1-1).

\begin{tabular}{lcc}
\hline \hline Uygulamalar & Verim $($ g/saksı) & Artış (\%) \\
\hline Kontrol & $114 \pm 6,66 \mathrm{~d}$ & 100 \\
$U$. rigida 3 & $126 \pm 5,57 \mathrm{~b}$ & 111 \\
Çiftlik gübresi & $128 \pm 5,29 \mathrm{a}$ & 112 \\
Algreen & $122 \pm 9,17 \mathrm{c}$ & 107 \\
\hline Önemlilik & $*$ \\
LSD 0.01 & 2,081 \\
\hline \hline Değerler tekerrür ortalanmasıdır & \\
*: p< 0,01 düzeyinde önemli & \\
1: Aynı sütunda farklı harflerle gösterilen ortalamalar arasındaki fark önemlidir
\end{tabular}

Tablo 7. U. rigida'nın farklı dozlarının fasulye verimine etkisi

\begin{tabular}{|c|c|c|}
\hline Uygulamalar & Verim (g/saksı) & Artış (\%) \\
\hline Kontrol & $114 \pm 4,58 \mathrm{f}$ & 100 \\
\hline$U$. rigida 1 & $115 \pm 4,36 \mathrm{e}$ & 101 \\
\hline$U$. rigida 2 & $116 \pm 5,13 \mathrm{~d}$ & 102 \\
\hline$U$. rigida 3 & $126 \pm 3,46 \mathrm{c}$ & 111 \\
\hline$U$. rigida 4 & $141 \pm 3,51 b$ & 124 \\
\hline$U$. rigida 5 & $150 \pm 2,52 \mathrm{a}$ & 132 \\
\hline Önemlilik & \multicolumn{2}{|c|}{$* *$} \\
\hline LSD 0.05 & \multicolumn{2}{|c|}{1,880} \\
\hline
\end{tabular}

Algler mineral, vitamin ve iz elementler bakımından zengindir. Alglerin mineral madde içeriği türlere, algin toplandığı yere, mevsimlere, çevresel ve fizyolojik faktörlere ve ürünün işlenme şekline göre değişim göstermektedir. U. rigida, Gracilaria verrucosa, Sargassum vulgare, Cystoseria barbata, Dictyopteris membranacae gibi kültüre alınmış alg türlerinin mineral ve oligo-element kompozisyonlarının belirlenmesini içeren bir çalışmada; $U$. rigida $\mathrm{Ca}, \mathrm{Ma}, \mathrm{Na}, \mathrm{K}, \mathrm{P}, \mathrm{Fe}, \mathrm{Cu}, \mathrm{Zn}$ ve $\mathrm{Mn}$ miktarlar1 sirasiyla 20333,3 $\pm 577,3 \mathrm{mg} / \mathrm{kg}, 10783,3 \pm 2266,2 \mathrm{mg} / \mathrm{kg}, 1220,0 \pm 0,0 \mathrm{mg} / \mathrm{kg}, 29200,0 \pm$ $519,6 \mathrm{mg} / \mathrm{kg}, 1172,0 \pm 35,4 \mathrm{mg} / \mathrm{kg}, 117,0 \pm 4,0 \mathrm{mg} / \mathrm{kg}, 14,0 \pm 4,3 \mathrm{mg} / \mathrm{kg}, 52,3 \pm 2,08 \mathrm{mg} / \mathrm{kg}$ ve 16,6 $\pm 2,0 \mathrm{mg} / \mathrm{kg} 1$ olarak saptanmıştır (Turan, 2007).

Kuru veya taze deniz alglerinin tarım arazilerinde kullanımının çok uzun yıllara dayandığını belirten araştırıcılar yaptıkları bir araştırmada farklı düzeylerde olgunlaşmış algleri Patagonya'da domates (Licopersicon esculentum Mill. cv. platense) yetişitiriciliğinde kullanmışlardır. Denemede kontrol, $5 \mathrm{~kg} \mathrm{~m}^{-2} 9$ aylık ve 20 aylık olgunlaşmış alg kompostu, $10 \mathrm{~kg} \mathrm{~m}^{-2}$ yine 9 ve 20 ay boyunca kompostlaşmış alg kullanmışlardır. Domateslerde toplam ağırlık, domates sayısı, biyokütle miktarlarının kontrole göre çok fazla arttığı rapor edilmiştir. Ayrıca alg ilave edilen parsellerdeki 
domateslerin 9 gün daha önce olgunlaştığını, hastalıklara daha dirençli olduklarını da belirlemişlerdir. 20 ay olgunlaştırılan alg materyal uygulamalarının 9 ay olgunlaştırılanlara göre tuz içeriklerinin de daha az olduğu rapor edilmiştir. Çalışmada kullanılan alg materyali bu araştırmada da toprağın fiziksel özellikleri yanında özellikle P ve K alınımını da arttıran kompostlaştırılmış alg uygulamasının pozitif etkili olduğu saptanmıştır (Eyras vd., 2013).

Mohamed ve Khaled (2005), Enteromorpha intestinalis, Enteromorpha linza, Ulva lactuca, Corallina mediterranea, Pterocladia capillacea gibi bazı yeşil alglerde $\mathrm{Cu}, \mathrm{Fe}, \mathrm{Mn}, \mathrm{Pb}$, and $\mathrm{Zn}$ 'nin dağılımını araştırmışlar ve farklı türlerin farklı derecelerde iz element içeriğine sahip olduğunu rapor etmişlerdir. Ho (1990), U. lactuca'nın $\mathrm{Mn}, \mathrm{Fe}, \mathrm{Cu}, \mathrm{Zn}$ gibi iz elementlerce zengin olduğunu saptamıştır.

İzmir Körfezi'nde dağılım gösteren $U$. rigida'nın en yüksek $\mathrm{Fe}, \mathrm{Cu}$ ve $\mathrm{Zn}$ konsantrasyonları sırasıyla 870,75 mg/kg (kış mevsiminde), 14,06 mg/kg (kış mevsiminde) ve 55,97 mg/kg (ilkbahar mevsiminde) olarak rapor edilmiştir (Çetingül, 1993).

$\mathrm{Bu}$ çalışmada $U$. rigida makro alginin kimyasal özelliklerini belirlemek amacıyla yapılan analizler algin organik madde, $\mathrm{N}, \mathrm{K}, \mathrm{Ca}, \mathrm{Mg}, \mathrm{Na}$ gibi makro element ve $\mathrm{Fe}, \mathrm{Cu}, \mathrm{Zn}$ ve $\mathrm{Mn}$ gibi iz elementler yönünden yeterli düzeyde olduğunu göstermiştir.

Organik tarımda yaygın bir kullanım alanı bulan çiftlik ve ithal deniz yosunu gübreleri bu çalışmada karşılaştırma grubu olarak kullanılan organik gübrelerdir. Denemeden elde edilen bulgular $U$. rigida alginin yeterli dozlar kullanıldığında fasulye bitkisi verimi üzerinde her iki organik gübreden de daha etkili olduğunu göstermiştir. Bu etki istatitiki açıdan da \%1 ( $\mathrm{p}<0.01 ; 2,081)$ düzeyde önemli bulunmuştur (Tablo 6). Denemede ayrıca, $U$. rigida alginin uygulama doz miktarını arttırdıkça fasulye veriminin de arttı̆̆ 1 ve uygulamanın 5. dozunun (150 g saks1-1) verim üzerinde en etkili uygulama olduğu tespit edilmiştir. Uygulama dozları ile verim arasındaki bu ilişki istatistiksel olarak \%5 ( $\mathrm{p}<$ $0.05 ; 1,880$ ) düzeyinde önemli bulunmuştur (Tablo 7). U. rigida makroalginin 5. dozu kontrol uygulamasına göre yaklaşık \% 32 civarında bir verim artışı sağlamıştır. Uygulanan bu doz deneme grupları arasında bulunan çiftlik gübresi ve ticari Algreen gübresinden de etkili bulunmuştur. Bitki besin maddeleri ( $\mathrm{N}, \mathrm{P}, \mathrm{K}, \mathrm{Ca}, \mathrm{Mg}$ vd.) bakımından da oldukça zengin olan bu materyal organik tarımda da rahatlıkla gübre olarak kullanılabilecektir.

Dünya genelinde ve Türkiye'de deniz yosunu özütlerinin etkinliğinin araştırılmasını konu alan birçok çalışma bulunduğu bildirilmektedir (Akman, 1995; Stirk ve Van Staden, 1996 ve 2004; Stirk vd., 2004). Günümüzde deniz yosunları birçok ülkede; gerek sıv1 ekstrakt gerekse direk olarak toprağa karıştırılmak suretiyle kullanılmaktadırlar. Toprağa direk olarak karıştırıldıklarında; toprak yapısının düzeltilerek, toprak verimliliğinin uzun süre korunması amaçlanmaktadır. Uzun yıllardan beri denizler tarafından doğal olarak kıyıya atılan bazı deniz algleri tarlalarda gübre olarak kullanılagelmiştir (Güner ve Aysel, 1996). Yosun özleri; meyve depo kayıplarının azaltılması, ürün miktarının, topraktan inorganik besin maddelerinin alınımının, tohum çimlenmesinin ve stres koşullarına direncin arttırılması gibi alanlarda özellikle gelişmiş ülkelerde organik tarımda daha fazla değerlendirilmektedir (Blunden, 1991). Kuvvetli kök gelişmesini sağlayarak, bitkilerin topraktan daha fazla besin maddesi ve su almalarını, bitkilerde klorofil oluşumunu hızlandırarak yeşil aksamın artmasını, bitkilerin hastalık ve zararlılara ve çevresel streslere dayanımını sağlarlar. Makro ve mikro besin elementlerinin topraktan dengeli olarak ve uzun süreli alınmasını sağlayarak verimi yükseltirler, kaliteyi düzeltir, pazar ve ihracat değerini arttırırlar (Blunden vd., 1992; Hong vd., 1995). Yağmur vd. (2010) yaptıkları çalışmada karasal bitkilere kıyasla daha fazla mineral madde içeren deniz yosunlarının değişik teknikler kullanılarak elde edilen ekstraktlarının alternatif gübre kaynağı olarak kullanılabileceği sonucuna varmışlardır. Türkiye iç pazarında satışa sunulan deniz yosunu kökenli organik gübreler dış alıma dayalı ürünlerdir. Ülkemizde bazı deniz yosunlarından elde edilen özütlerin konvansiyonel ve organik tarımda kullanılabilirliği konusunda yapılmış çalışmaların materyalini dış alıma dayalı bu ürünler oluşturmaktadır.

Akman (1995), Maxicrop ve bazı büyüme düzenleyicilerinin yuvarlak çekirdeksiz üzüm bağlarında asmanın verim, gelişme, olgunluk ve kalite değerlerine etkilerini incelemiş, Maxicrop'un 2000 $\mathrm{mg} / \mathrm{kg}$ 'lik dozunun verim ve salkım sayısını arttırıcı, buna karşılık tane iriliğini ise azaltıcı yönde etkileri olduğunu saptamıştır. Beşiroğlu (1992), Antalya Seracılık Araştırma Enstitüsünde hibrit dario F1 çeşidi domatese maxicrop ile birlikte 4 farklı bitki gelişim düzenleyicisini uygulamış ve en yüksek meyve veriminin (\% 29,3) Maxicrop ile sağlandığını bildirmiştir. Uncu ve Arığlu (2005), ikinci ürün 
erken ekimlerinde uygulanan Maxicrop ve Cytozyme'in geç olgunlaşan soya çeşitleri üzerinde etkili olduğunu verim ve verim unsurlarının iyileşmesini sağladığını bildirmiştir.

$\mathrm{Bu}$ çalışma, ülkemiz kıyılarında doğal olarak yayılım gösteren bazı makroalglerin alternatif gübre kaynağı olarak kullanım olanaklarını araştıran ilk çalışma olması nedeniyle konuyla ilgili yapılacak çalışmalara kaynak oluşturacağını ümit etmekteyiz. Ülkemizde denize kıyısı olan birçok şehirde kıyı kirliliğine de neden olan bu materyallerin tarımsal üretimde kullanılabilirliği ve bitkisel üretime katk1 sağladığı da bu çalışma sonucunda ortaya konulmuştur.

Teşekkür: Bu çalışma EÜ BAP kapsamında desteklenen 2007 SÜF-002 no'lu projeden üretilmiştir.

\section{KAYNAKLAR}

Açıkgöz, N., Akbaş, M. E., Özcan, K., \& Moghaddam, A.F. (1994). Tarımsal araştırmaların değerlendirilmesi için PC Paketi TARISST, Tarla Bitkileri Kongresi 25-29 Nisan 1994. E.Ü. Ziraat Fakültesi Bornova-İzmir.

Ak, İ. (2015). Sucul ortamın ekonomik bitkileri; makro algler. Dünya Glda Dergisi,7, 88-97.

Akman, İ. (1995). Yuvarlak çekirdeksiz üzüm bağlarında ve Amerikan asma çeliklerinde bazı gelişmeyi düzenleyici maddelerin etkilerinin belirlenmesi üzerine araştırmalar. E.Ü. Fen Bilimleri Enst. Bahçe Bitkileri ABD., Doktora Tezi, 42-43.

Anonim, (2015) . Algreen ithal deniz yosunu gübresinin kimyasal özellikleri. www.izotar.com.tr

Ay, H. (1994) . Çukurova bölgesi koşullarında, deniz yosunu özü "Ascphyllum nodosum" Maxicrop ile deniz yosunu süspansiyonu "Durvilla patatorum" Kelpak' ın, pamuğun (Gossypium hirsutum L.) morfolojik, fizyolojik ve teknolojik özelliklerine etkileri üzerine bir araştırma. Çukurova Üniversitesi Fen Bilimleri Enstitüsü Tarla Bitkileri Anabilim Dalı Yüksek Lisans Tezi, 8-26.

Beşiroğlu, A. (1992). Amfora F1 domates hibriti çeşidine Maxicrop ve Maxialg uygulamaların ön etkisi üzerinde bir deneme raporu. Seracılık Araştırma Enst.Müdürlüğü, yayınları, 1-42.

Bingham, T.F. (1949). Soil test for phosphate: New method of chemical analysis of soil for available phosphate is rapid and accurate. California Agriculture 3(8), 11-14.

Black, C.A. (1965) . Methods of soil analysis. Part I. Amer. Soc. of Agro. Inc. Wisconsin, 1572.

Blunden, G., (1991). Agricultural uses of seaweeds and seaweed extracts. In: Seaweed Resources in Europe: Uses and Potential. Pp.65-81.

Blunden G., Whapham, C., \& Jenkıns, T., (1992). Seaweed extracts in agriculture and horticulture: Their origins, uses and modes of action. School of Pharmacy and Biomedical Science and "School of Biological Sciences, University of Portsmouth, King Henry John Street, Portsmouth, Hampshire P01 202, U.K.

Bouyoucos, G.J. (1962). Hydrometer method improved for making particle size analysis of soil. Agronomy Journal, 54, 464-465.

Bremner, J.M. (1965). Inorganic Forms of Nitrogen. In: Black, C.A., et al., Eds., Methods of Soil Analysis, Part 2, Agronomy Monograph, 9, 1179-1237.

Cirik, Ş., Uysal, H., Parlak, H., Demirkurt, E., \& Küçüksezgin, F. (1988). Heavy metal accumulation by marine vegetation in pulluted waters of İzmir bay. International Symposium on Plants and Pollutants in Developed and Developing Countries. 22-28 August, İzmir, 33-38.

Cirik, Ş., \& Cirik, S. (1999). Su bitkileri:I deniz bitkilerinin ekolojisi, biyolojisi ve yetiştirme teknikleri. Ege Üniversitesi, Su Ürünleri Fakültesi Yayınları, 58,135-145.

Cirik, Ş. (2001). Gökova körfezi deniz bitkileri. D.E.U. Deniz Bilimleri ve Teknolojisi Enstitüsü, Piri Reis Yayinlart, 3, 26-38.

Çetingül, V. (1993). Ekonomik değerdeki bazı deniz alglerinin kimyasal içeriklerinin saptanması. Ege Üniversitesi Fen Bilimleri Enstitüsü Biyoloji Ana Bilim Dalı, Doktora Tezi, 15-27.

Çetingül, V., \& Aysel, V. (1998). Ekonomik değerdeki bazı kahverengi ve kırmızı alglerin ağır metal birikim düzeyleri. Ege Üniversitesi Su Ürünleri Fakültesi Dergisi, 15(1-2), 63-76.

Çetingül, V. (2001). Petalonia fascia (O.F. Müll.) Kuntze'nın biyokimyasal kompozisyonunun mevsimsel değişimi. Ege Üniversitesi Su Ürünleri Fakültesi Dergisi, 18(1-2), 117-124.

Demir, H.,Topuz, A., Gölükçü, M., Polat, E., Özdemir, F., \& Şahin, H. (2006). Ekolojik üretimde farklı organik gübre uygulamalarının domatesin mineral madde içeriği üzerine etkisi. Akdeniz Üniversitesi Ziraat Fakültesi Dergisi, 16(1), 19-25.

Demirkurt, E., Uysal, H., \& Parlak, H.(1990). The levels of heavy metals accumulation in some benthic organisms living in İzmir Bay. Rapp. Comm.. Mer Medit.,32(1) 170-174.

Erdin, N., \& Özsöz, Ş.(1983). Deniz alglerinin anorganik element içerikleri. Ege Üniversity Faculty of Science Journal Series B, Supply, 501-507

Eşiyok, D., Yağmur, B., \& Okur, B. (2001). The effects of some naturel and mineral fertilizers on yield and mineral content of parsley(Petroselinum crispum Mill.). 37 th Croatian symposiumon agriculture with an int. participation., 19-23 February. Opatija, 179-181. 
Eşiyok, D., \& Bozokalfa, MK. (2007). Fasulye yetiştiriciliği. Dünya Yayıncılık, Gıda Dergisi, 6, 88-90.

Eyras, M.C., Defossé G.E., \& Dellatorre, F. (2013). Seaweed compost as an amendment for horticultural soils in Patagonia, Argentina. Compost Science and Utilization 16, (2),119-124

Favero, N., Cattalini, F., Calderara, D., \& Albergoni, V. (1996). Metal accumulation in a biological indicator ( Ulva rigida) from the Lagoon of Venice (Italy). Environmental Contamination and Toxicology 31(1), 918

Güllüoğlu, L., \& Arığlu, H.H. (2005). Farklı yetiştirme koşullarında uygulanan bazı bitki büyüme düzenleyicilerinin soyada (Glycine max Merr.) bakla çatlama oranı ve verim kaybı üzerine etkileri. Harran Üniversitesi Ziraat Fakültesi Dergisi, 9 (1), 37-42.

Güner, H., \& Aysel, V., (1996). Tohumsuz bitkiler sistematiği. 1. Cilt (Algler). Ege Üniversitesi Fen Fakültesi Kitaplar Serisi, No.108, Bornova, İzmir.

Ho, Y.B. 1990. Ulva lactuca as bioindicator of metal contamination in intertidal waters in Hong Kong. Hydrobiologia, 203, 73-81.

Hong, Y.P., Chen, C.C., Cheng, H.L., \& Lyn, C.H., (1995). Analysis of auxin and cytokinin activity of commercial Aqueous Seaweed Extract. Gartenbauwissenschaft, 60(4),191-194.

Kacar, B. (1972). Bitki ve Topră̆ın Kimyasal Analizleri. II. Bitki Analizleri, A.Ü. Ziraat Fak. Yayınları: 453, $22-78$

Kacar, B. (1984). Bitki Besleme. Ankara Üniversitesi Ziraat Fakültesi Yayınları, 899, 169-175

Kaykaç, O.G., Cirik, Ş., \& Tekinay, A.G. (2008). Yeşil deniz alglerinden Ulva rigida (C. Agardh)'nın besin kompozisyonu ve aminoasit içeriklerinin mevsimsel değişimi. Ege Üniversitesi Su Ürünleri Fakültesi Dergisi, 25(1), 9-12.

Koç, H. (2013). Giresun sahillerinden toplanan bazı deniz makroalglerinden (Ulva sp., Cystoseira sp. ve Corallina sp.) organik gübre üretim yöntemleri ve gübrelerin bitki besin elementlerinin belirlenmesi. T.C. Giresun Üniversitesi Fen Bilimleri Enstitüsü Biyoloji Anabilim Dalı Yüksek Lisans Tezi, 65.

Koru, E., \& Cirik, S. (1999). Alglerin tarım ve endüstride kullanımı. Türkiye I. Ekolojik Tarım Sempozyumu, 21-23 Haziran 1999, İzmir, 344.

Kut, G.B., Cirik, Ş., Güroy, D., Sanver, F., \& Tekinay, A.A. ( 2007). Effects of Ulva rigida or Cystoseira barbata meals as a feed additive on growth performance, feed utilization, and body composition in Nile tilapia, Oreochromis niloticus". Turkish Journal of Veterinary and Animal Science, 31(2), 91-97.

Lindsay, W.L., \& Norvell, W.A. (1978). Development of a DTPA soil test for Zn, Fe, Mn and Cu. Soil Science Society of America Journal, 42(3), 421-428.

Loot, W.L., Nerry, J.D., Gallo, J.R., \& Medcoff, J.C. (1956). Leaf analysis technique in coffe research, IBEC. Research Institue. II, (9), 21-24

Lopez, M.E., \& Pazos, M. (1997). Effects of seaweed on potato yields and soil chemistry. Journal of Biological Agriculture and Horticulture, 14, 199.206.

Meteoroloji Genel Müdürlüğü, (2016). 2014-2015 Yılı İzmir ili Bornova ilçesi ortalama, maksimum ve minimum sıcaklık ile nispi nem değerleri. www.mgm.gov.tr

Mohamed, L.A., \& Khaled, A. (2005). Comparative study of heavy metal distribution in some coastal seaweeds of Alexandria, Egypt. Chemistry and Ecology, 21(3), 181-189.

Murthy, M.S., \& Radia, P. (1978). Ecobiochemical studies on some economically important intertidal algae from Port Okha (India). Botanica Marina, 21, 417-422.

Okur, B., Eşiyok, D., \& Anaç, D. (2001). Effect of mineral and organic fertilizers on leaf nitrogen compounds of rocket (Eruca vesicaria subsp. sativa Mill). 37th Croatian Symposium on Agriculture. 19-23 February, Opatija-Croatia, 188-189.

Özdemir, S. Sukatar, A., \& Öztekin ,G. (2016). Chlorella vulgaris Üretimi ve Sera Organik Domates Yetiştiriciliğinde Biyogübre Olarak Kullanımının Etkileri. Tarım Bilimleri Dergisi, 22, 596-605 Ankara.

Özilbey, N. (1997). Zeytinde bazı bitki büyüme düzenleyicileri ve yaprak gübrelerinin mahsul miktarı ve kalitesine etkileri üzerine bir araştırma.. E.Ü. Fen Bilimleri Enstitüsü Bahçe Bitkileri Anabilim Dalı, Doktora Tezi , 2-23.

Öztürk, M. (1994). Sinop'un koy ve limanlarında yayılım gösteren Patella coerulae L. ve Enteromorpha linza (L.) 1. Agardh türlerindeki ağır metal düzeyleri. Turkish Journal of Biyology, 18, 195-211.

Pratt, P.F. (1965). Methods of Soil Analysis. Part 2. Chemical and Microbiological Properties. In: C.A. Black, (Ed.). American Society of Agronomy, Inc. Pub. Agron. Series, No. 9., Madison, Wisconsin, U.S.A.,146195

Sawidis,T., \& Voulgaropoulus, A. (1986). Seasonal bioaccumilation of 1ron,cobalt and copper in marine algaea from Thermaikos Gulf of Northern Aegean Sea. Greece. Marine Environmental Research, 19(1), 39-47.

Soil Survey Staff, (1993). Soil Survey Manuel. USDA Handbook No:18, Washington,USA, 18-25.

Stenner, R.D., \& Nickless, G. (1974). Distrubition of some heavy metals in organisms in Hardangerfjord and Skjerstadfjord, Norway. Water Air Soil Pollution, 3, 279-291. 
Stirk, W.A., \& Staden, V.J. (1996). Comparison of cytokinin- and auxinlike activity in some commercially used seaweed extracts. Journal of Applied Phycology, 8, 503-508.

Stirk, W.A., \& Van Staden, J. (2004). Potential new applications for the Southern African kelps. South Africa Journal Botanic, 70, 145-151.

Stirk, W.A., Arthur, G.D., Lourens, A.F., Nov'ak, O., Strnad, M., \& Staden, V.J. (2004). Changes in cytokinin and auxin concentrations in seaweed concentrates when stored at an elevated temperature. Journal of Applied Phycology, 16, 31-39.

Talbot, V., \& Chegwidden, A. (1986). Cadmium and other heavy metal concentrations in selected biota from Cockburn Sound, Western Australia. Australian Journal of Marine and Freshwater Research, 33(5), 779788

Turan, M., \& Köse, C. (2004). Seaweed extracts improve copper uptake of grapevine, Acta Agriculture Scandinavica, Section B-Soil and Plant Science, 54, 213-220.

Turan, G. (2007). Su yosunlarının thalassoterapi' de Kullanımı. E.Ü. Fen Bilimleri Enst. Su Ürünleri Yetiștiricilik Anabilim Dalı, Doktora Tezi, 125-129.

Uncu, A.H., \& Arığlu, H.H. (2005). İkinci ürün soya tarımında farklı ekim zamanlarına göre bazı büyüme düzenleyicilerin verim ve kalite üzerine etkileri Türkiye VI. Tarla Bitkileri Kongresi, 5-9 Eylül 2005, Antalya. 375-380

U.S. Salinity Laboratory Staff, .(1955). Diagnosis and improvement of saline and alkali soils. Agri. Handbook No: 60, USDA, 38-59.

Vinogradov, A.P. (1953). The elementary chemical composition of marine organisms. Sears Found, Mar. Res., Mem. II.New Haven, 647.

Yağmur, B., Engin, Ö.Y., Okur, B., \& Cirik, S., (2010). Gracilaria verrucosa (Hudson) Papenfuss kırmızı deniz alginden farklı yöntemlerle elde edilen ekstraktların mineral madde içerikleri. 5. Ulusal Bitki Besleme ve Gübre Kongresi 15-17 Eylül 2010 İzmir. Bildiriler Kitabı, Ege Üniversitesi Ziraat Fakültesi Dergisi Özel Sayl,676-684.

Yeşiloğlu, T., \& Tuzcu, Ö. (1993). Klemantin mandarininde GA3 ve bilezik alma uygulamalarının bitki besin elementleri düzeyine etkileri. Doğa Türk Tarım ve Ormancılık Dergisi, 17(1), 149-167. 